Article

\title{
Sustainable Lighting Policies: The Contribution of Advertisement and Decorative Lighting to Local Light Pollution in Seoul, South Korea
}

\author{
Jack Ngarambe and Gon Kim * \\ Department of Architectural Engineering, Kyung Hee University, Yongin 446-701, Korea; ngarajack@khu.ac.kr \\ * Correspondence: gonkim@khu.ac.kr
}

Received: 6 March 2018; Accepted: 28 March 2018; Published: 29 March 2018

check for updates

\begin{abstract}
We carried out field measurements to determine the contribution of advertisement and decorative lighting to local light pollution in Seoul. We used the lighting limits set by the "Light Pollution Prevention Act", which regulates light pollution, as measuring criteria. Our results show that both advertisement and decorative lighting are significant contributors to local light pollution in Seoul. Thirty percent of advertisement lighting measured in our study areas exceeded the legal limits. Moreover, we found that certain types of advertisement lighting are more likely to cause light pollution than the others. In addition, $73 \%$ of the decorative lighting found in our sample areas exceeded the legal limits. Based on our findings, we suggest that local light pollution policies establish a curfew time when all advertisement and decorative lighting must be completely turned off. Such an approach is essential in reducing lighting levels in outdoor environments. Furthermore, it lessens the burden on law enforcement personnel, who otherwise must ensure that advertisement and decorative lighting levels are kept within the legal limits. In light of the ongoing debate over the role of lighting in public well-being and the sustainability of cities, the present study provides a discussion on the status and management policy of light pollution caused by advertisement and decorative lighting.
\end{abstract}

Keywords: light pollution; surface luminance; advertisement lighting; decorative lighting; urban policies; light trespass

\section{Introduction}

Artificial lighting is arguably the greatest recent achievement of humankind. It has become an integral part of the urban environment. However, artificial lighting, especially Artificial Lighting At Night (ALAN), has been linked to health conditions such as diabetes [1], breast cancer in women [2,3], fatigue and depression [4]. In addition to the health effects associated with artificial lighting, skyglow caused by ALAN also has been reported to be a major hindrance to astronomical activities $[5,6]$ and the primal behavior of wildlife [7]. The collective adverse effects of artificial lighting are known as light pollution. The severity of light pollution has warranted governmental intervention in many parts of the world. The Czech Republic was the first nation to place legal limits on the use of outdoor artificial lighting. Other countries, including France and Slovenia [8], soon followed. South Korea is the most recent country to enact a law limiting the use of artificial lighting and thus reducing light pollution [9]. A major facet of light pollution legislation in South Korea deals with advertisement and decorative lighting. In the past, street lighting and security lighting were considered to be the main causes of certain types of light pollution, such as light trespass and light clutter. More recently, there has been a rapid increase in advertisement signboards and permanent decorative lighting on restaurants, hotels and motels. This kind of outdoor lighting, especially in residential and mixed-use 
areas, has led to an increased number of civil complaints [10] related to light trespass that interferes with the sleeping patterns of neighboring residents. Excessive brightness from billboard signs and decorative lighting may also cause visual discomfort to pedestrians [11,12]. We carried out a field survey in order to determine the extent to which outdoor lighting from advertisement signboards and decorations contributes to local light pollution in Seoul. In addition, we discuss the current governmental management policy regarding light pollution control and its effectiveness in reducing light pollution caused by decorative and advertisement light sources.

\subsection{Advertisement Lighting in Korea}

Advertisement lighting is defined under Paragraph 2 of Article 2 of the "Light Pollution Prevention Act" of South Korea. It is defined as "light emitting equipment and auxiliary devices that light outdoor signs for advertisement purposes" [12]. For the purpose of this study, we considered static (i.e., non-moving) advertisement lighting installed on building facades. Existing advertisement lighting in Korea was categorized into four types based on the lighting mechanism: flex, channel letter, external floodlight and neon. Figure 1 shows an example of each type of lighting. Flex lighting (Figure 1a) consists of a light source, such as fluorescent tubes or light emitting diodes (LEDs), mounted within an enclosure with the desired design. When the light source is turned on, it projects a silhouette of the design, forming a colorful and attractive image. These kinds of advertisement signs produce light with high luminance. As such, they are likely to cause significant discomfort, especially in dark, residential neighborhoods. Channel letter lighting (Figure 1b) is a three-dimensional, modern type of advertisement lighting that is normally made of aluminum and acrylic, where each letter is lit individually using LEDs. Channel letter signboards often radiate high levels of surface brightness and therefore are likely to cause both light trespass and glare. External floodlight advertisements (Figure 1c) are signs that usually do not contain inner imbedded lighting. Instead, the lighting is installed on the outside and shines onto the sign, making it bright and visible. In cases where the background of the signage or the signage itself is made of highly reflective material, light projected onto the sign can be reflected far away, causing light trespass. Neon signs are usually fitted with neon tubes and are used in signage with graphic elements (Figure 1d). More detailed descriptions of the classification of advertisement lighting in Korea are provided by Ko et al. [13] and Cho et al. [14]

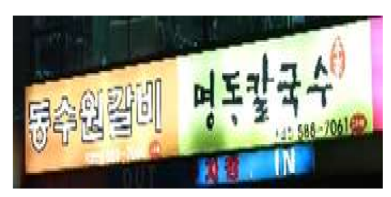

(a)

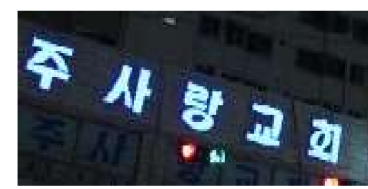

(b)

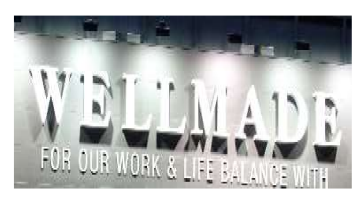

(c)

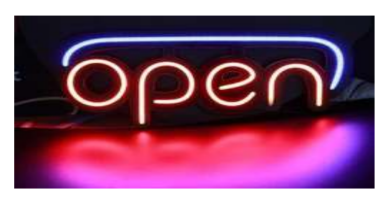

(d)

Figure 1. Categories of advertisement lighting: (a) Flex; (b) Channel letter; (c) External floodlight; (d) Neon.

\subsection{Decorative Lighting in Korea}

Decorative lighting is defined in Paragraph 3 under Article 2 of the "Light Pollution Prevention Act" of South Korea as "Lighting installed on building facades for decorative purposes or those installed on recreational facilities, accommodations or buildings with decorative lighting" [12]. In most light pollution legislation, pollution caused by decorative lighting is addressed under seasonal or event lighting. Seasonal decorations such as Christmas lighting and event lighting such as lighting at concerts may not be a great source of discomfort to local neighborhoods, as they occur only a few times each year. In Korea, however, decorative lighting such as the examples shown in Figure 2, is common and consistent throughout the year. These kinds of decorative lighting may result in bright and consistent sources of visual discomfort to local residents. As a result, Korea puts more emphasis on limiting decorative lighting than other countries do. 


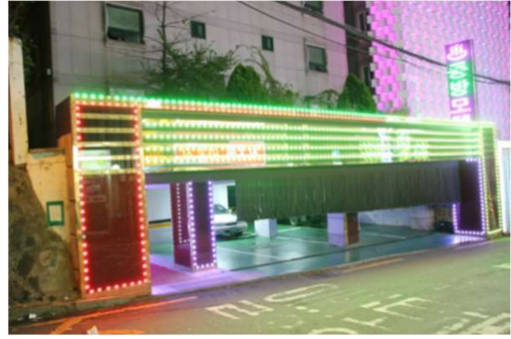

(a)

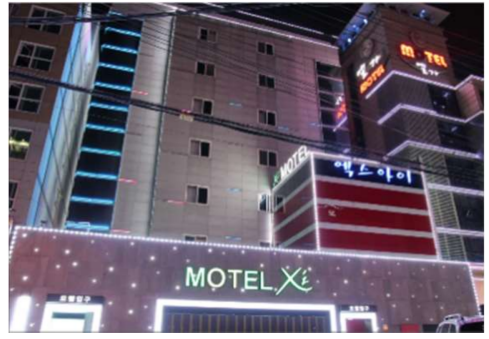

(b)

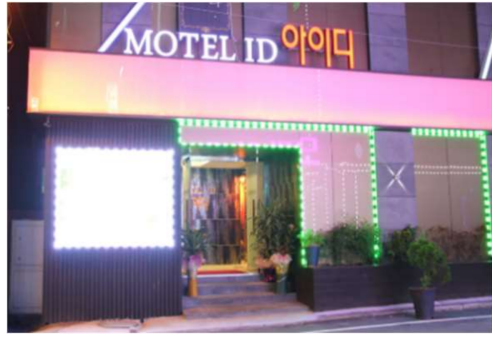

(c)

Figure 2. (a) Decorative lighting on a hotel parking entrance; (b) Decorative lighting on a building façade; (c) Decorative lighting on a hotel entrance.

\section{Legal Lighting Limits}

As briefly mentioned above, the regulation of outdoor lighting is not a new concept. Institutions such as the Commission Internationale de l'Eclairage (CIE) [15], the Illuminating Engineering Society of North America (IESNA) [16] and the International Dark-Sky Association (IDA) [17] have suggested setting lighting limits based on the function of a given area. Areas that require light pollution control are designated into different lighting management zones depending on the amount of light needed, so that outdoor lighting is not restricted equally in all areas. For example, lighting in a commercial, urban area may be brighter than the lighting in a residential area. Although the usefulness of lighting management zones has been questioned considering that light travels, and lighting activities in one management zone can easily affect activities in a neighboring zone, most regulations still adopt the "lighting management zone" concept. Most decrees and local ordinances that regulate the usage of outdoor lighting, including those of South Korea, follow a zone classification system similar to that of the CIE [15]. Perhaps the only difference between the classification of lighting zones by the South Korean law and that by the CIE is that the CIE recently added a zone catering to astronomical observation areas. Table 1 shows the lighting environmental management zones established by the "Light Pollution Prevention Act."

Table 1. Lighting environmental management zones of South Korea.

\begin{tabular}{cl}
$\begin{array}{c}\text { Lighting Environmental } \\
\text { Management Zone }\end{array}$ & \multicolumn{1}{c}{ Description } \\
\hline LZ 1 & Areas where artificial lighting might affect the natural environment \\
\hline LZ 2 & $\begin{array}{l}\text { Areas where high levels of artificial lighting might affect agriculture } \\
\text { and crop productivity }\end{array}$ \\
\hline LZ3 & $\begin{array}{l}\text { Exclusive residential and ordinary residential areas where lighting is } \\
\text { mainly needed for safety, comfort and security }\end{array}$ \\
\hline LZ 4 & $\begin{array}{l}\text { Industrial, commercial and semi-residential areas where lighting is } \\
\text { mainly needed for comfort and commercial activities. }\end{array}$ \\
\hline
\end{tabular}

For each lighting management zone, the South Korean law provides lighting limits for both advertisement and decorative lighting. For advertisement lighting, the limits are based on maximum permissible luminance values $\left(\mathrm{cd} / \mathrm{m}^{2}\right)$, whereas for decorative lighting, the limits specify average and maximum permissible luminance values $\left(\mathrm{cd} / \mathrm{m}^{2}\right)$ within each lighting environmental management zone. Table 2 shows the allowable maximum luminance values for each lighting environmental zone for both decorative and advertising lighting. The limits are applied, one hour after sunset and one hour before sunrise. 
Table 2. Legal limits of decorative and advertisement lighting.

\begin{tabular}{|c|c|c|c|c|c|c|}
\hline \multirow{2}{*}{ Lighting Type } & \multirow{2}{*}{$\begin{array}{l}\text { Light Parameter } \\
\qquad\left(\mathrm{cd} / \mathrm{m}^{2}\right)\end{array}$} & \multirow{2}{*}{ Applicable Period } & \multicolumn{4}{|c|}{$\begin{array}{l}\text { Lighting Environmental } \\
\text { Management Zones }\end{array}$} \\
\hline & & & LZ 1 & LZ 2 & LZ 3 & LZ 4 \\
\hline $\begin{array}{l}\text { Advertisement } \\
\text { lighting }\end{array}$ & $\begin{array}{l}\text { Maximum } \\
\text { luminance }\end{array}$ & $\begin{array}{l}\text { One hour after sunset to } \\
\text { one hour before sunrise }\end{array}$ & 50 & 400 & 800 & 1000 \\
\hline \multirow{2}{*}{$\begin{array}{l}\text { Decorative } \\
\text { lighting }\end{array}$} & $\begin{array}{l}\text { Average } \\
\text { luminance }\end{array}$ & \multirow{2}{*}{$\begin{array}{l}\text { One hour after sunset to } \\
\text { one hour before sunrise }\end{array}$} & 5 & 5 & 15 & 25 \\
\hline & $\begin{array}{l}\text { Maximum } \\
\text { luminance }\end{array}$ & & 20 & 60 & 180 & 300 \\
\hline
\end{tabular}

\section{Field Measurements}

\subsection{Selection Criteria for Survey Areas}

We selected survey areas based on a number of factors to ensure that they were representative of the variety of areas that experience severe light pollution. Floating population is an important factor because areas frequented by a high number of people at night tend to have brightly lit signboards and/or decorative lighting to attract more customers [14]. The presence of night clubs and convenience stores, which tend to have bright lights, was another important factor. To account for the brightly lit signboards in residential neighborhoods, we obtained data on lighting-related civil complaints from the Seoul metropolitan police database. This data allowed us to pinpoint the areas with the highest number of civil complaints related to artificial lighting; these areas were included in the investigation. In total, we inspected 97 areas in Seoul: 13 residential areas, 10 semi-residential areas, 3 industrial areas and 71 commercial areas.

\subsection{Tools of Measurement and Analysis}

We used a Canon EOS 500 (Canon, Tokyo, Japan) camera with LMK (Luminance Measuring Kamera) to capture photo imagery. LMK was developed by Techno Team and is used to evaluate lit areas where aerial-based monitoring methods are found to be expensive and difficult to use. Images taken with LMK store data related to luminance and color of a lit environment. Luminance values can then be extracted from the picture using LMK LabSoft software (Ver. 12.7.3) (Techno Team, Berlin, Germany). The software displays luminance data as color maps, where each color represents a different luminance value. Figure 3 shows an example of typical images used in the study, including a luminance map created using LabSoft. To improve accuracy in our measurements, we took several images with different exposure times (shutter speeds) for a single target billboard sign or decorative light. We then combined the images into a single high dynamic range (HDR) image. After obtaining HDR images, we used LabSoft to obtain maximum and average luminance values for every advertisement billboard sign and for every decorative lighting installation found in the surveyed areas. The use of HDR photography as a luminance-mapping tool has been validated based on analytical and comparative studies $[18,19]$. To validate the measured results, we also used a secondary luminance-measuring device, CS-100 (Konica Minolta, Tokyo, Japan).

\subsection{Measurement Method}

To avoid interference from sunlight, all field measurements were conducted after sunset. In extreme cases light reflections from a snow covered-ground can radiate into the light-measuring camera increasing the attenuation of noise in a luminance image. Measurements were made on clear days to avoid inaccuracies caused by weather conditions such as rain, fog and snow. As reported by Lim et al. [20], luminance measurements using light cameras are affected by both the angle and the distance of measurement. For this reason, the National Institute of Environmental Research of Korea 
(NIERK) suggests that, when assessing signboards for light pollution using light cameras, researchers should endeavor to capture the entire signboard image. In cases where it is impossible to capture full images due to obstructions such as trees or passing vehicles, researchers are encouraged to capture images at an angle between 0 and 30 degrees. The NIERK also suggests that the measuring equipment (light-measuring camera) be at least $1.5 \mathrm{~m}$ above the ground and placed parallel to the target source of light [10]. In this study, this suggestion was taken into consideration. Figure 3 shows an example of the analysis process.

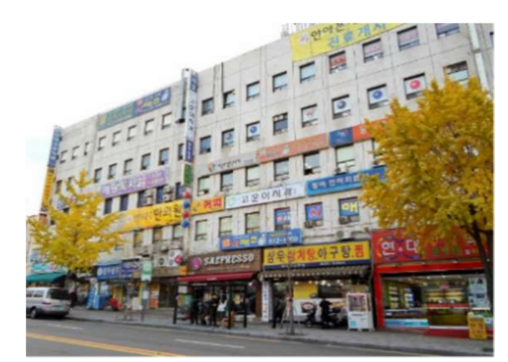

(a)

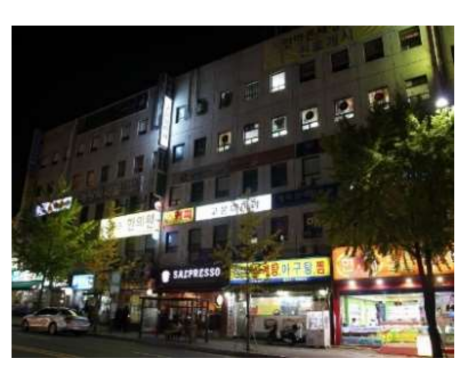

(b)

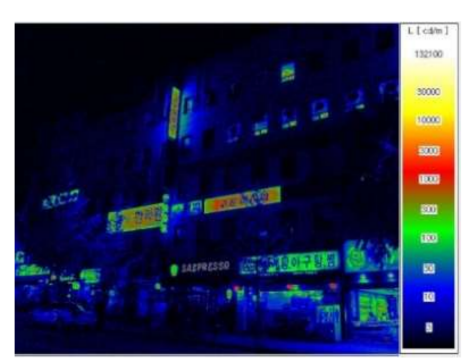

(c)

Figure 3. Analysis process: (a) Daytime image; (b) Nighttime image; (c) Analysis image.

\section{Results}

We calculated the percentage of advertisement or decorative lighting installments in each land usage category that surpassed the maximum allowable luminance value set by the act. The maximum permissible luminance values used for advertisement lighting in residential and commercial areas were $800 \mathrm{~cd} / \mathrm{m}^{2}$ and $1000 \mathrm{~cd} / \mathrm{m}^{2}$, respectively (refer to Table 2). In areas where commercial and residential activities co-existed, i.e., semi-residential areas and industrial areas, the dominant activity in the study area was used to select the maximum allowable luminance value. For example, if a target advertisement signboard was located in a part of a semi-residential area where commercial activities were more prevalent than residential activities, the $1000 \mathrm{~cd} / \mathrm{m}^{2}$ limit value was used.

For decorative lighting, maximum permissible luminance values of $180 \mathrm{~cd} / \mathrm{m}^{2}$ and $300 \mathrm{~cd} / \mathrm{m}^{2}$ were used as measuring criteria in residential and commercial areas, respectively. Similarly, in areas where commercial and residential activities co-existed, i.e., semi-residential areas and industrial areas, either the $180 \mathrm{~cd} / \mathrm{m}^{2}$ or $300 \mathrm{~cd} / \mathrm{m}^{2}$ limit was applied, depending on the dominant activity in the area.

\subsection{Advertisement Lighting and Pollution}

Figure 4 shows the percentage of advertisement lighting installations, regardless of type, that exceeded the maximum allowable luminance level specified by the law in residential and commercial areas. In residential areas, $39 \%$ of the total number of investigated advertisement lighting installations exceeded the legal limit. In semi-residential areas, industrial areas and commercial areas, $28 \%, 39 \%$ and $30 \%$ of the surveyed advertisement installations, respectively, also exceeded the legal limit. Additionally, we found that residential areas and industrial areas showed the highest percentage of advertisement lighting installations that exceeded the maximum luminance values dictated by the law.

Figure 5 shows the percentage of advertisement lighting installations that exceeded the maximum allowable luminance values based on type of advertisement lighting. In residential areas, $76 \%$ of external floodlights, $45 \%$ of channel letter lighting and $21 \%$ of flex lighting advertisements radiated light whose average luminance value exceeded the legal limit. Neon advertisement lights were almost non-existent in residential areas. In the surveyed residential areas, we found only one neon advertisement light and its average luminance value was lower than the legal limit. In semi-residential areas, $66 \%$ of external floodlights, $54 \%$ of channel letter and $12 \%$ of flex advertisement lights exceeded the legal limit. There were no neon advertisement lights in the surveyed areas. In industrial areas, $100 \%$ 
of external floodlight advertisement lights, $64 \%$ of channel letter and $22 \%$ of flex advertisement lights exceeded the legal limit. Again, there were no neon advertisement lights installed in the surveyed industrial areas. Finally, in commercial areas, $63 \%$ of external floodlight, $26 \%$ of channel letter, $18 \%$ of flex and $7 \%$ of neon advertisement lights exceeded the legal limit.

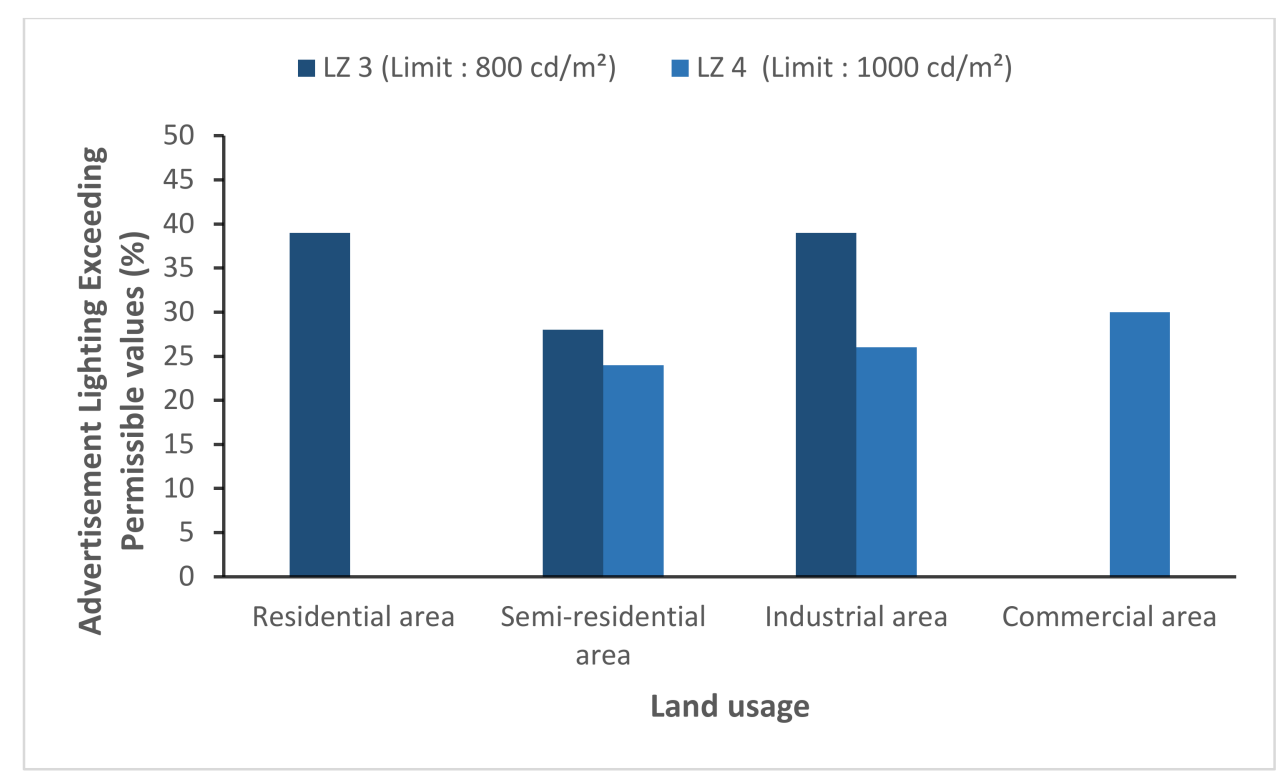

Figure 4. Percentage of advertisement lighting installations exceeding maximum permissible luminance values.

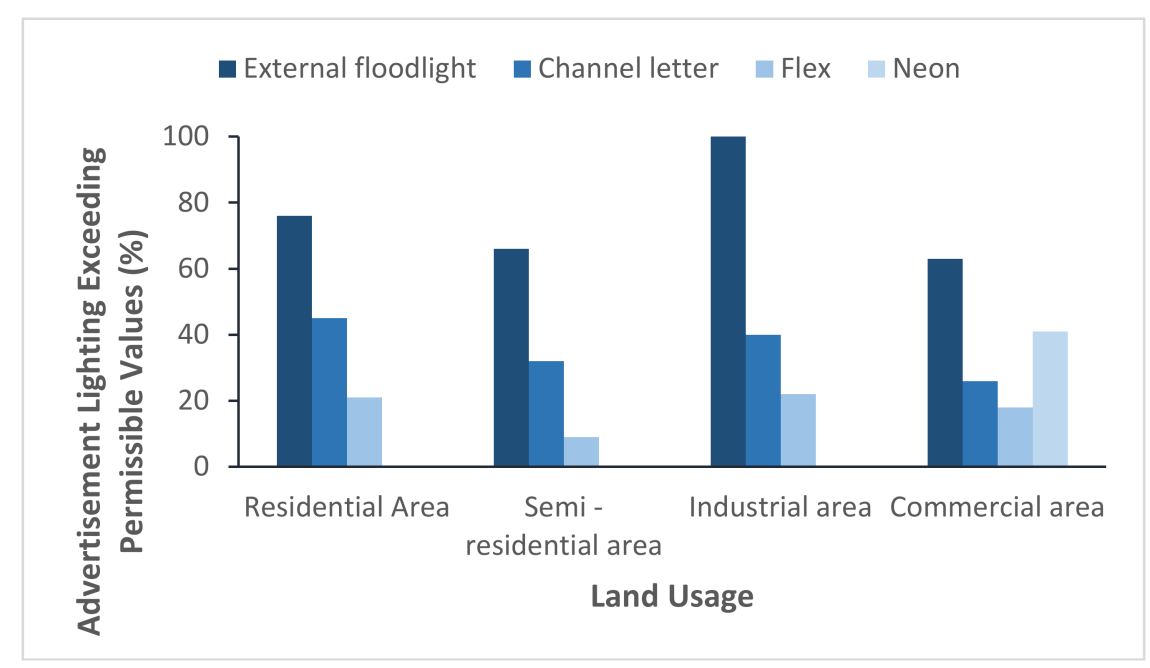

Figure 5. Percentage of advertisement lighting exceeding maximum permissible luminance values categorized by light type.

The highest number of advertisement lights that exceeded the legal limit across all land-use categories belonged to the external floodlight type. In addition, neon advertisement lights were uncommon in all investigated areas. A few neon advertisement lights were found, mainly in commercial areas. 


\subsection{Decorative Lighting and Pollution}

Figure 6 shows the percentage of decorative lighting installations that exceeded the legal limit. In the investigated residential areas, $86 \%$ of decorative lighting installations exceeded the legal limit. In semi-residential areas, $100 \%$ of decorative lighting installations exceeded the $180 \mathrm{~cd} / \mathrm{m}^{2}$ limit, whereas $88 \%$ exceeded the $300 \mathrm{~cd} / \mathrm{m}^{2}$ limit. In industrial areas, $56 \%$ and $44 \%$ exceeded the $180 \mathrm{~cd} / \mathrm{m}^{2}$ and $300 \mathrm{~cd} / \mathrm{m}^{2}$ limits, respectively. In the surveyed commercial areas, $72 \%$ of decorative lighting installations exceeded the legal limit.

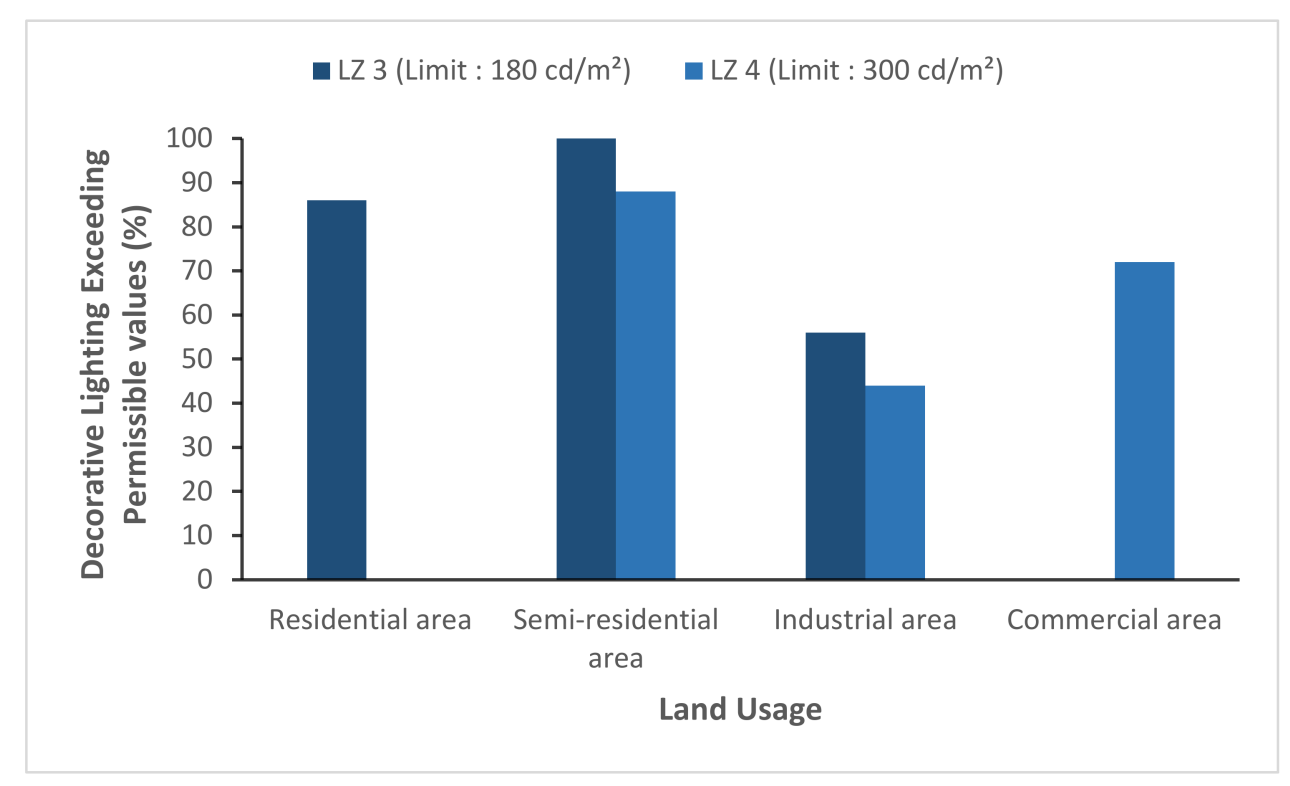

Figure 6. Percentage of decorative lighting installations exceeding maximum permissible luminance values.

\section{Discussion}

For the purposes of the current study, light pollution is defined as any amount of light surpassing the maximum luminance values dictated by the law. Our results show that both advertisement and decorative lighting contribute significantly to local light pollution. Furthermore, our results show that the external floodlighting type of advertisement lighting is most likely to cause light pollution.

These findings have far-reaching implications concerning light pollution and light pollution policies because, as noted earlier, the debate surrounding outdoor lighting and light pollution has mostly focused on security and street lighting [21]. For this reason, many lighting institutions such as the ILE (Illuminating Engineering Society, New York, NY, USA) [22] and IESNA [23] provide recommendations for reducing excessive lighting from street and security lamps, but not for advertisement or decorative lighting. For instance, street and security lighting designers are advised to use full cutoff or semi-cutoff luminaires to minimize the spread of backward and upward lighting. Such recommendations are not provided for designers of advertisement and permanent decorative lighting, however. To that end, professional design recommendations that guide advertisement and decorative lighting designers on how to avoid light pollution without necessarily sacrificing their intended purpose are warranted.

Furthermore, light pollution legislation from many countries including the Light Pollution Prevention Act of South Korea and recommendations from lighting institutions such as the CIE [15] dictate lighting limits that are not to be exceeded depending on the area of the advertisement or decorative lighting. While the approach of setting lighting limits may reduce the spread of unwanted lighting somewhat, it faces three major shortcomings, especially regarding sleep disturbance and public complaints. 
First, in areas where residential buildings are in very close proximity to advertisement signboards such as from convenience stores and decorative lighting from local businesses, following the lighting limits set by the law is unlikely to prevent unwanted lighting from radiating into residential buildings through windows or other existing openings.

Second, it is difficult to know if the surface luminance from a given signboard or decorative lighting installation exceeds the legal threshold without using light measuring equipment. For this reason, most local businesses are unaware that they are violating lighting laws. Similarly, local residents are unsure of whether a given signboard or decorative lighting is violating the law and are thus reluctant to involve law enforcement. It is also possible, as discussed by Kim et al. [24], that people might be unaware of the lighting laws that are meant to protect them from unwanted and harmful lighting.

Third, and perhaps most importantly, the lighting regulations provide lighting limits for individual advertisement signboards. While this approach is useful in areas where there are few signboards installed on separate parts of the building façade, it is not very helpful where a cluster of signboards are concentrated on one part of a building façade. It is possible for each individual advertisement signboard on a façade to radiate surface luminance value below the legal threshold while at the same time, the net luminance radiated by all the signboards installed on the façade is enough to cause unwanted changes in the ambient environment. Furthermore, as also discussed by Ho and Lin [25], the coverage area of the advertisement signboard contributes to the amount of light radiated; larger signboards tend to have higher surface luminance values as compared to smaller signboards.

To solve some of the issues discussed here, the Korean government should consider setting a curfew time at which all local businesses must completely turn off their advertisement and decorative lighting. A good example of the curfew system is one applied by the French government to all public lighting at night [8]. Establishment of such a curfew time in Korea would provide an added advantage of energy savings. In addition, the coverage area of advertisement signboards should be considered when setting legal lighting limits; in general, the lighting limit for large signboards should be higher than that of small signboards. Furthermore, in areas where mixed-use development is common, i.e., commercial shops on the lower floors and residential rooms on upper floors, as is commonly seen in Seoul and many Asian cities such as Tokyo, Beijing, Taiwan etc., local policies should establish an additional luminous management zone to cater for mixed-use areas. This would facilitate the establishment of stricter regulations in mixed-use areas where the control of light pollution is more complicated than in purely residential or commercial areas.

Future research should assess the contribution of decorative and advertisement lighting in other parts of Korea. It would be helpful to lawmakers to see how the rest of Korea compares to the capital, Seoul. That way, lawmakers would know where to direct their focus. It would also be informative to see how South Korea compares to its developed neighbors where advertisement and decorative lighting are prevalent such as Japan and China.

It is also important to realize how different legal approaches to light pollution control, the type of light pollution legislation and the level of implementation may affect light pollution control.

There are three common approaches to light pollution control. The first one is based on the amount of light emitted and how it can be limited. The second one is based on curfew time; time of the night when all outdoor or indoor lighting must be reduced to a certain level or extinguished. The third approach entails a combination of both limits and curfews. For example, legislation in France utilizes the curfew approach. France's legislation does not focus solely on reducing skyglow, light trespass, etc., the measures taken also address energy conservation issues. Under the law, all indoor lights should be turned off one hour after the last person has left a commercial building. Furthermore, commercial and non-residential buildings are to turn off any form of outdoor lighting between the period of 1 a.m. and 7 a.m. [26]. This approach, while generally effective, it has certain limitations. For example, 1 a.m. maybe considered quite late into the night and as such, lighting may still cause disturbances to 
people who sleep before the curfew time ( 1 a.m.), especially children. Most new legislation dealing with light pollution control utilize a combination of both "lighting limits" and "curfew". Legislation utilizing both the "curfew" and "lighting limits" system such as the Slovene [27] and South Korean [9] legislation tend to be more effective than legislation that employ only one of the two systems; "lighting limits" or "curfew". However, as pointed out earlier, they also have certain limitations, particularly concerning advertisement and decorative lighting. Further studies that examine the effectiveness of each type of approach are therefore warranted.

Furthermore, as discussed by Morgan-Taylor [28], there are two common types of light pollution legislation; "stand alone" legislation and "add-on" legislation. "Stand-alone" laws are created to address the specific issue of light pollution whereas "add-on" laws are mere extensions of already existing legislation to include light pollution control. "Add-on" legislation such as the one adopted in England [8] and the Czech Republic [29] possess an economic advantage, as they require less time and resources to implement. However, being that such laws are extensions of the already existing legislation, they do not fully address issues that are specific to light pollution. For instance, the English legislation defines light pollution as "artificial light emitted from premises so as to be prejudicial to health or a nuisance" [30]. Such inexplicit definitions fail to include serious light pollution issues such as skyglow. Generally, "stand-alone" legislation tend to be more effective than "add-on" laws. This is because they address specific issues that are directly caused by unwanted light.

There are also issues that arise because of the level at which light pollution legislation is implemented. Regional legislation or ordinances as opposed to national legislation are becoming common. These are specific to certain regions or cities within a country. Generally, regional or city ordinances tend to address light pollution control based on activities peculiar to a given region or city. For example, many provinces of Italy passed laws, mainly aimed at reducing skyglow and preventing hindrances to astronomical activities [31]. The logic here is that since astronomical activities are dominant in Italian provinces such as Lombardy, light pollution control measures that prevent skyglow should be more intensive. There are also several states or cities such as Bothell city in Washington DC (USA) [32], Beijing (China) [33], Bisei (Japan) [34], Catalonia (Spain) [35], etc., that have passed regional laws to address light pollution control. In most cases, regional ordinances are adopted to combat specific light pollution issues that are caused by activities prevalent in a given city or province. Advocates for regional-based legislation argue that national-based legislation over generalize issues that are caused by light pollution and thus reducing their effectiveness. On the other hand, advocates for national-based legislation argue that light pollution concerns that are caused by specific activities in a given region can be addressed through the zoning system instead of incurring extra costs creating light control legislation based on regional activities. It is unclear which of the two types of light pollution legislation is more effective. Therefore, future studies should examine and compare the effectiveness of regional and national light pollution legislation.

\section{Conclusions}

In the present study, we carried out field investigations in order to determine the contribution of advertisement and decorative lighting to local light pollution in Seoul. We found that, indeed, advertisement and decorative lighting are major sources of light pollution. Our findings also show that channel letter signboards emit less light compared to other advertisement lighting types. As such, channel letter signboards are better options for a sustainably-lit environment. Additionally, we found that the current measures taken by international lighting institutions as well as those by the Korean light pollution law need reinforcements to better control light pollution from advertisement and outdoor decorative lighting. Consequently, we suggest that an additional luminous management zone to cater for mixed-land use areas be established. We also suggest that coverage area of the advertisement lighting and the number of advertisements that exist on a façade be considered when deciding lighting limits for light pollution control. 
Acknowledgments: This work was supported by the Ministry of Environment, Republic of Korea and the Seoul Metropolitan Government.

Author Contributions: Jack Ngarambe participated in the process of measuring data, analysis of the luminous environment, and documentation of the study. Gon Kim led the construction of the manuscript and his academic skill on both lighting pollution and assessment provided the knowledge on how to measure the luminous data and to draw conclusion in the study.

Conflicts of Interest: The authors declare no conflict of interest.

\section{References}

1. Hu, C.; Jia, W. Linking MTNR1B variants to diabetes: The role of circadian rhythms. Diabetes 2016, 65, 1490-1492. [CrossRef] [PubMed]

2. Lunn, R.M.; Blask, D.E.; Coogan, A.N.; Figueiro, M.G.; Gorman, M.R.; Hall, J.E.; Hansen, J.; Nelson, R.J.; Panda, S.; Smolensky, M.H.; et al. Health consequences of electric lighting practices in the modern world: A report on the National Toxicology Program's workshop on shift work at night, artificial light at night, and circadian disruption. Sci. Total Environ. 2017, 607, 1073-1084. [CrossRef] [PubMed]

3. Schernhammer, E.S.; Kroenke, C.H.; Laden, F.; Hankinson, S.E. Night work and risk of breast cancer. Epidemiology 2006, 17, 108-111. [CrossRef] [PubMed]

4. Weinert, D.; Waterhouse, J. Interpreting circadian rhythms. In Biological Timekeeping: Clocks, Rhythms and Behaviour; Springer: New Delhi, India, 2017; pp. 23-45.

5. Liu, M.; Zhang, B.G.; Li, W.S.; Guo, X.W.; Pan, X.H. Measurement and distribution of urban light pollution as day changes to night. Light. Res. Technol. 2017. Available online: https:/ /doi.org/10.1177/1477153517740751 (accessed on 28 March 2018). [CrossRef]

6. Kyba, C.C.; Kuester, T.; de Miguel, A.S.; Baugh, K.; Jechow, A.; Hölker, F.; Bennie, J.; Elvidge, C.D.; Gaston, K.J.; Guanter, L. Artificially lit surface of Earth at night increasing in radiance and extent. Sci. Adv. 2017, 3, e1701528. [CrossRef] [PubMed]

7. Bliss-Ketchum, L.L.; de Rivera, C.E.; Turner, B.C.; Weisbaum, D.M. The effect of artificial light on wildlife use of a passage structure. Biol. Conserv. 2016, 199, 25-28. [CrossRef]

8. Morgan-Taylor, M. Regulating Light Pollution in Europe: Legal Challenges and Ways Forward; Routledge: Abingdon, UK, 2015.

9. Cha, J.S.; Lee, J.W.; Lee, W.S.; Jung, J.W.; Lee, K.M.; Han, J.S.; Gu, J.H. Policy and status of light pollution management in Korea. Light. Res. Technol. 2014, 46, 78-88. [CrossRef]

10. Lim, H.S.; Ngarambe, J.; Kim, J.T.; Kim, G. The Reality of Light Pollution: A Field Survey for the Determination of Lighting Environmental Management Zones in South Korea. Sustainability 2018, 10, 374. [CrossRef]

11. Sim, Y.J.; Kim, I.T.; Choi, A.S.; Sung, M.K. A preliminary study of an evaluation method for discomfort glare due to light trespass. Light. Res. Technol. 2017, 49, 632-650. [CrossRef]

12. Ministry of Environment, Korea. Light Pollution Prevention Act in Korea; Chapter 1; MOE: Seoul, Korea, 2013.

13. Ko, T.K.; Kim, I.T.; Choi, A.S.; Sung, M.K. Quantitative assessment methods for determining luminous environmental zones in Korea. Light. Res. Technol. 2016, 48, 307-322. [CrossRef]

14. Cho, H.M.; Lee, M.K.; Chang, S.J.; Kim, S. Analysis on Luminance of Outdoor Signboards of Commercial Areas in Seoul at Night Considering Light Pollution. J. Korean Soc. Living Environ. Sys. 2015, 22, 583-589. [CrossRef]

15. CIE 150:2003. Guide on the Limitation of the Effects of Obtrusive Light from Outdoor Lighting Installation; CIE: Vienna, Austria, 2003.

16. Illuminating Engineering Society of North America. Light Trespass: Research, Results and Recommendations; TM-11-2000; IESNA: New York, NY, USA, 2000.

17. International Dark Sky Association. Outdoor Lighting Code Handbook; IDA: Tucson, AZ, USA, 2002.

18. Cai, H.; Chung, T.M. Improving the quality of high dynamic range images. Light. Res. Technol. 2011, 43, 87-102. [CrossRef]

19. Inanici, M.N. Evaluation of high dynamic range photography as a luminance data acquisition system. Light. Res. Technol. 2006, 38, 123-134. [CrossRef] 
20. Kim, G.; Amina, I.; Lim, H.S.; Kim, J.T. The impact of distance on the accuracy of luminance measurement. Energy Procedia 2014, 62, 612-618. [CrossRef]

21. Stone, T. Light pollution: A case study in framing an environmental problem. Ethics Policy Environ. 2017, 20, 279-293. [CrossRef]

22. Institute of Lighting Engineers. Guidance Notes for the Reduction of Obtrusive Light; ILE: Rugby, UK, 2005.

23. Illuminating Engineering Society of North America. American National Standard Practice: Roadway Lighting; RP-8-00; IESNA: New York, NY, USA, 2000.

24. Kim, K.H.; Choi, J.W.; Lee, E.; Cho, Y.M.; Ahn, H.R. A study on the risk perception of light pollution and the process of social amplification of risk in Korea. Environ. Sci. Pollut. Res. 2015, 22, 7612-7621. [CrossRef] [PubMed]

25. Ho, C.Y.; Lin, H.T. Analysis of and control policies for light pollution from advertising signs in Taiwan. Light. Res. Technol. 2015, 47, 931-944. [CrossRef]

26. An Introduction to French Light Pollution Law. Available online: http://public-law.net/publaw/view.aspx? id=1818 (accessed on 20 March 2018).

27. Vertačnik, G. Slovenian Light Pollution Legislation. In Proceedings of the 4th International Symposium for Darksky Parks, Cellers, Spain, 27 June-1 July 2011; Volume 28.

28. Morgan-Taylor, M.; Kim, J.T. Regulating Artificial Light at Night: A Comparison Between the South Korean and English Approaches. Int. J. Sustain. Light. 2016, 18, 21-31. [CrossRef]

29. The Czech Act on Protection of the Air, including Light Pollution Prevention. Available online: http: / / amper.ped.muni.cz/light/law / czairlaw3.htm (accessed on 21 March 2018).

30. The Statutory Nuisances (Miscellaneous Provisions) (Wales) Regulations 2007. Available online: http: / / www.legislation.gov.uk/wsi/2007/117/regulation/3/made (accessed on 20 March 2018).

31. Zitelli, V.; Di Sora, M.; Ferrini, F. Local and national regulations on light pollution in Italy. In SymposiumInternational Astronomical Union; Cambridge University Press: Cambridge, UK, 2001; pp. 111-116.

32. Bothell Municipal Code. Available online: http://www.codepublishing.com/WA/Bothell/html/BothellNT. html (accessed on 22 March 2018).

33. Laws of the Beijing Province. Available online: http://www.asianlii.org/cn/legis/bj/laws/ robmgoaoobi927/ (accessed on 20 March 2018).

34. Isobe, S.; Sugihara, N. Light-pollution Prevention Ordinance in the Town of Bisei. Publ. Astron. Soc. Aust. 1991, 9, 336-337. [CrossRef]

35. Schwarz, H.E. Light pollution control: World-wide effects of and efforts to reduce light pollution. In Organizations and Strategies in Astronomy; Springer: Dordrecht, The Netherlands, 2003; pp. 37-57. 